\title{
Effects of Road Traffic Congestion on Economic Activities of Dar es Salaam Region in Tanzania
}

\author{
Helena A. Lwesya ${ }^{1} \quad$ Laurencia Ndelamo Massawe $^{2} \quad$ Lucas P. Mwisila $^{3 *} \quad$ Haidari P. Misafi ${ }^{4}$ \\ 1.Department of Logistics and Transport Studies, The National Institute of Transport P.O.Box 705 \\ Dar Es Salaam \\ 2.Department of Mathematics, Humanities and Social science, The National Institute of Transport P.O.Box 705 \\ Dar Es Salaam \\ 3.Department of Science and Management, Dar es Salaam Maritime Institute P.O.Box 6727 \\ Dar Es Salaam \\ 4.Department of Business and Entrepreneurship Studies, National Institute of Transport, P.O. Box 705, \\ Dar es Salaam
}

\begin{abstract}
The general objective of this study was to examine the effects of road traffic congestion on economic activities of Dar es Salaam Region in Tanzania. The findings show that congestion is caused by narrow roads, bad road conditions, rainfall, non-operating traffic lights, double parking, inadequate feeder-roads, road accidents, road work, many pedestrians crossing the road and many bumps in the roads. Also, congestion on average increases costs of fuel by Tsh. 32,167.00 paid from bus drivers' pocket and reduces productive time of workers by 2.5 hours. Similarly, employees with formal employment got up between 3:00am and 4:00am early in the morning to avoid road congestion but due to unreliable transport services employee with income of Tsh. 90,000.00 spend 39\% of the income as fare because they pay twice in a single journey. However, during their return home they are easily caught in congestion as they get home late at $22: 00 \mathrm{pm}$. Therefore, congestion affects the economy by reducing the turnover, profit margin and sales of individuals and in aggregates the economic activities of Dar es Salaam region. This study recommends that, roads be enlarged and pedestrian bridges, feeder-roads and bumps be constructed in a way that reduces congestion.
\end{abstract}

Keywords: Road Traffic Congestion and Economic Activities

DOI: $10.7176 / \mathrm{JESD} / 12-6-05$

Publication date:March $31^{\text {st }} 2021$

\section{Introduction}

Road congestion is a problem emanated from the effects of urbanisation, according to Tanzania Transport Sector Review (2013), the fast urbanisation growth has reduced the capacity of cities in terms of infrastructures and quality of services needed by urban residents. Dar es Salam city like other developing cities in Africa is vulnerable of road congestion as one of the effects of urbanisation. According to Kiunsi (2013), traffic congestion is attributed by the factors such as increase in population, inadequate infrastructures, increase in cars, increase of social and economic activities, and lack of city plan and development. This research study was based on "Effects of Road Traffic Congestion on Economic Activities of Dar es Salaam Region in Tanzania”. According to Maji (2017), Dares Salaam is witnessing the increasing number of cars and traffic congestion specifically, during daytime (noon) and sunset (peak hours). Road traffic congestion has substantial effect on economic activities of individual and the community through delay, transport costs, safety and emission from cars.

Various studies have been carried on in regard of traffic congestion and its effects. The study on traffic congestion by Elisenguo (2013), examined the social economics impact of road congestion and found that public transport system in Dar es Salaam little meet the basic needs of its inhabitant. Likewise, Angus and Betram (2019) assessed the contemporary awareness of the effects of congestion on traffic and accidents; and found that an inverse relationship between accidents and congestion would imply a benefit of congested conditions for road safety, posing a difficult situation for traffic management. Moreover, Onyeneke et al (2018) modelled the effects of traffic congestion on economic activities, accidents, fatalities and casualties; and found that traffic growth and number of registered vehicles in urban areas are linked with growing number of accidents and fatalities. Accidents account for a significant share of recurring delays. As traffic increases, people feel less safe to use the roads. It is observed that traffic congestion in urban centres could be viewed as a result of mandatory daily trips such as workplace, home, school or voluntary. Nevertheless, all these studies provide little insights on the extent the road traffic congestion affects the economic activities of Dar es Salaam region. This study provides an insight on the extent the road traffic congestion affects the economic activities of individual economies which in turn are the aggregate of Dar es Salaam region Economy.

\section{Review of Literature}

The road congestion occurs when the demand for traffic surpasses the capacity of the road network; the situation 
results in a decrease in the speed of moving vehicles or total prevention of free movement (Bull, 2013 and Raheem et al, 2015). Normally traffic jam occurs during peak hours in morning and evening, according to Hartgen and Fields (2017), traffic jam is a line of stationary or very slow-moving traffic, caused by road works, an accident, or heavy congestion. Angus and Bertram (2019) define traffic jam as a situation in which a long line of vehicles on a road have stopped moving or are moving very slowly. Peak hours are a part of the day during which traffic congestion on roads and crowding on public transport is at its highest. The term is often used for a period of peak congestion that may last for more than one hour Hartgen and Fields (2017). A peak hour is a part of the day during which traffic congestion on roads and crowding on public transport is at its highest Lomendra et al (2018). Normally, this happens twice a day once in the morning and once in the evening, the times during when the most people commute. The term is very broad but often refers to specifically private automobile transportation traffic, even when there is a large volume of cars on a road but not a large number of people, or if the volume is normal but there is some disruption of speed Elisenguo (2013).

\subsection{Economic effects of road congestions}

Economic growth is the increase in the production of economic activities. The economic activities are conducted within different sectors like health, agriculture, tourism, insurance, transport, education, banking, mines, energy, construction, and many more Onyeneke et al (2018). According to Boldeanu and Constantinescu (2015), it was reported that economic activity is the increase of GDP or GDP per capita, an augmentation of national product that is measured in constant prices. Chizonde (2016), portrays economic activities as influenced by direct factors such as human resource, capital and natural resources. An economic activity is also influenced by indirect factors such as institutions (financial institutions, private and administrations). The size of the aggregate demand, saving rates and investment rates, the efficiency of the financial system, budgetary and fiscal policies, migration of labour and capital and the efficiency of the government. There are four major determinants of economic activity: people, natural resources, capital formation and advancement of technology Lomendra et al, (2018). Some studies put forward the relationship between transportation and productivity as a well-established transportation system triggers economic development $\mathrm{Lu}$ et al., (2009). Eddington (2006) as noted in Upreti (2015) argues that road congestion is costly for a country's economy. Likewise, Choi et al. (2013) and Elisenguo (2013) stipulates that fuel consumption and depreciation of vehicles are due to traffic congestion. Industries with higher levels of truck shipping absorb higher costs associated with congestion and thus benefit more from congestion reduction. The statistical analysis also shows that firms with non-specialised commodity input requirements tend to be hurt relatively less by congestion, and benefit relatively less from congestion reduction than those with requirements for highly specialised material inputs. All city-dwellers are also adversely affected, in terms of deterioration in their quality of life through such factors as greater air and noise pollution and the negative long-term impact on the healthiness and sustainability of their cities, all of which make it vitally necessary to keep congestion under control.

\section{Research Methodology}

In this study the cross-sectional research design was employed, which involved observation of time spent on traffic congestion, factors leading to road traffic congestion and economic activities concerned in order to explore the role of traffic congestion to economy activities. This was due to the methods used that enabled the researcher to examine several respondent groups at a single point in-time as suggested by Bailey (2014). Both qualitative and quantitative data were collected using research instruments including documentary review, questionnaires and interviews. The study was conducted in four (4) major roads (highways) leading to city center and major markets in Dar es Salaam. The main roads and their specific areas are: first, Morogoro road; the study in this route was conducted at Ubungo junction, Magomeni mapipa, and Mbezi mwisho. Second, Mandela road; the studied areas are Tazara, Riverside, Tabata junction, and Buguruni sheli. Third; Kilwa road, data were collected in the following area :Kurasini, Kwa Azizi Ali and Mbagala rangitatu; and fourth Nyerere road; data were collected at Kamata, Vingunguti, and Banana/Njiapanda Segerea. In the same perspective, a total of 67 respondents were given the questionnaires and returned them dully filled, and 30 respondents were interviewed. Data were collected in the morning (observation) and in the evening (observation). Interview was conducted in the afternoon and questionnaires were distributed as it was possible meet with the respondent (drivers, passengers, vendors and pedestrians) during lunch time and during this time traffic is at easy Data collected were scientifically analysed and report presentation made.

\section{Discussion and Findings}

The general objective of this study was to determine the effects of road traffic congestion on economic activity of Dar es Salaam region. The study examines the causes leading to road traffic congestion in Dar es Salaam region and determined the factors influencing economic activity Dar es Salaam region 


\subsection{Causes of Leading to Road Traffic Congestion}

\subsubsection{Double Parking and Lack of Feeder- roads}

Double packing in the road is due to lack of parking slots in the City, lack of publicly owned car parking leads drivers to park on both sides of the road which is mostly done by drivers of semi-trailers, trucks and petrol tanks. It is evident the city has fewer feeder-roads as compared to the number of vehicles available in Dar es Salaam, and most of feeder roads are constructed below standards, which make them to last for one to two years. Parking vehicles along both side of the road is allowed by the City Council in some specific areas due to lack of appropriate parking slots in the City. Likewise, lack of feeder-roads is due to poor planning, where most of people live in unplanned areas with no roads and other essential public goods. Feeder-roads play an essential role in reducing congestion in the main roads (highways). In Dar es Salaam, the fact that they are fewer, cause huge concentration of vehicles in the highways which leads to congestion. These findings are similar to Lomendra et al. (2018) who found that among other factors, lack of sufficient feeder-roads in a mega city leads to huge volume of cars in the principal roads, which end up in causing congestion.

\subsubsection{Road Accidents and Increased number of Trucks in the road}

This implies that respondents have agreed that road accidents cause road congestion. These findings are similar to (Angus et al, 2019) who found that there is an inverse relationship between accidents and congestion would imply a benefit of congested conditions for road safety, posing a difficult situation for traffic management, and the economy at large. In the same regard, the findings show an increasing trend and most of those accidents occurred in Dar es Salaam. As consequences, these accidents did not only lead to traffic congestions, but also took human lives and destructions of properties including vehicles; which have adverse effects on the economy. The findings show that unattended road accidents cause long congestion than the attended one. Most of defected cars in the midst of the road are semi-trailers, trucks, and old commuter buses. These vehicles cannot easily be removed by "breakdown services" due to their tonnage, this require them to leave until they are repaired. By the time it is being repaired, it causes traffic congestion which affects the economy, not only of the owner of the defected vehicle, but also of those stuck on the jam due to vehicle condition. Also the increase in number of trucks without road expansion leads to congestion, lomendra (2018), found that the overflow of vehicles on the limited road space causes terrible road traffic congestion; the long traffic congestion which has effects on the economy.

\subsubsection{Road work and Narrow Roads}

Road work, if there is major road construction projects affects the lanes, and lower the efficiency of our work. It was noticed that in all major road construction projects there were signs that the road work is on-going. But specifically those road works consisting of maintenance and repair there were no signs for the minor road work like road holes, and heaving removing. Likewise, some drivers and motorists do not follow the signs leading to unnecessary traffic jams. Also, the narrow roads with huge volume of cars cause traffic congestion. The findings also show that Mandela and Morogoro roads which are frequented and used by large and heavy vehicles, each lane has 2.8 to 3 meters which means one side of these highways has 5.6 to 6 meters large, which is insufficient as the these roads are used by large, long and heavy vehicles. The number of lanes in these four roads as compared to the volume of vehicles using the roads proves that the narrow roads are the cause of road congestion. These findings are similar to Tilak \& Reddy, (2016) who found that the overflow of vehicles on the limited road space is a major cause of road congestion in most cities of developing countries.

\subsubsection{Lack of road traffic signs and Bumps}

Road signs cannot cause road congestion directly, instead the lack of those signs cause road accidents which in turn cause road congestion. In the same regard, too many bumps in the road slower the speed of the vehicles which then lead to road traffic congestion. The bumps are not found in the highways of Dar es Salaam, but they are found at Banana-Nyerere road and Gongo la Mboto. These bumps are not good, they make the movement to be too slow, and they also cause defections to vehicles especially if the driver wants to quickly pass at those bumps.

\subsubsection{Pedestrians crossing the road}

When many pedestrians cross the road at the same time or found in the road at the same time can cause road congestion. These findings are correlated to the ones found by Lomendra et al. (2018) that huge number of people on the roads at the same time cause of congestion especially in high density areas in the city. This really proves that these findings are accurate and valid. Other factors that cause road congestion are bad road conditions.

\subsubsection{Bad Road Conditions and Non-operating traffic lights}

The road conditions are: having holes caused by rainfall, and holes caused by removal of old tarmac. There is a challenge of the quality of our roads, especially in times of rain season. Most of the roads has a lifespan of 5, 10 and 20 years, these roads require frequent maintenance, but we fail to conduct maintenance on time that is why heaving and holes occur. These holes and heaving in our roads cause long traffic congestion as drivers lower the speed to zero in the areas where roads are in bad conditions to avoid causing defections to their vehicles. Likewise, traffic lights fixed in different junctions in Dar es Salaam use solar power and Electricity; some factors leading to non-operating of traffic lights are malfunctioning of the traffic lights which require reparation, the solar based traffic lights do not operate when it is night, and electricity (power) cut-off. When traffic lights do not operate, it 
is normally seconded by a traffic Police officer. But in case there are no lights nor police officer, then the congestion is normally dense which leads to a jam, for every driver want to be the first to pass.

\subsection{Effects of Road Congestion on the Economic Activities}

The road congestion leads to low business turnover among business owners in Dar es Salaam, especially the middle and some small businesses. These businesses are affected by the jam because they are conducted business owners, Business turnover is used to estimate the revenue, out of which the tax is calculated. With this situation business suffer when there is road congestion. In the same regard, and as a consequence of the low turnover, the profit margin also goes down. These findings are similar to that of Elisenguo (2013) who found that road congestion causes loss of output, missed deliveries, reduced productivity hence lowering profit margin. Similarly, the study by Osang (2010) found that congestion compromises moving freely and disrupts business activities in cities and reduces productivity. Reduction in productivity affects negatively the activities of the city and the country as a whole.

Likewise, road congestion increases fuel consumption. The findings show that vehicles (commuters) spend more than two hours in the congestion which increases the fuel consumption by average of Tsh 32,167.00 when stuck on congestion for two 2.5 hours or more. This lowers the amount of money they are supposed to get as they buy fuel from their own pocket and not from the bus owner. By average they are supposed to get Tsh. 47,167.00 per day in absence of congestion and by average Tsh. 15,000.00 when road congested hence individual turnover diminishes similarly with increase in bus turnaround time. Congestion does dot only affects the earnings of commuter driver and conductors, but also that of the commuter-owner. These findings are related to Elisenguo (2013), stipulated that fuel consumption and depreciation of vehicles are due to traffic congestion, which means that congestion increases not only the fuel consumed by vehicles but also affects the value of the vehicle through depreciation. In the same regard, the findings are supported by the urban transport economic theory which entails that the production cost increases with congestion and productivity lowered Arnott (2011). The findings in this flow show that respondents have agreed that road congestion causes wastage of working hours to people who normal use commuter and own private vehicles. On the other hand workers spend minutes on average on the congested road which affects not only the time they spend while going to or leaving from work, but also affects their performances.

Congestion affects workers' productivity and the performance of the whole company. These findings are supported by the (Elisenguo, 2013) found that road congestion causes late arrival to workplaces, which affect productivity. In this regard, the time spend on a traffic congestion diminishes the normal working hours of the employee, which affect the company as a whole. Contrary to the above discussion, the findings show that, the congestion is beneficial to small venders along the road congestion. The longer the congestion the more likely the vendor will have sold many items/products they have, and directly increasing his earnings per day. The findings were emphasised by Mpogole and Msangi (2016) who studied the traffic congestion in Dar es Salaam on implication for workers' productivity and found that 2.5 hours were lost on traffic jam per day assuming an 8 hour work day; thus in every 10 working days almost 3 days were lost on traffic congestion. However, the workers with formal employment are not very much affected by congestion because they have changed completely their sleeping time table. These workers got up early in the morning starting from 3.00am to 4:00am to catch up the public transport services and they arrive at their working places before opening the offices. Similarly, those who provide services such as "Mama and Baba lishe" are not affected as they got up early to avoid the traffic congestions. Nevertheless, these employees, on their way back home got home at around 22:00pm so they have at most 5hours to sleep. These workers include those paid wages at rate of Tsh. 3000 to Tsh. 5000 per day summing up to Tsh. $90,000.00$ to Tsh. $150,000.00$ and those employed by the Government. Moreover, because transport is not reliable it doesn't matter to wake up early or late in terms of fare paid. Normally it is twice ranging from Tsh. 1600 to Tsh.2000 from home to working place and back home. Considering a month of 22 working days and the bus fare of Tsh.1600 the sum of transport is Tsh. 35,200. The fare bus is substantial and is $39 \%$ for an income of Tsh. 90,000.00. Public transport services for that matter need to be improved in order to be reliable, effective and affordable.

\section{Conclusion and Recommendations \\ 5.1 Conclusion}

Road traffic congestion has much negative effects to the economy than the positive impacts it brings. The findings affirm that the causes that lead to road congestion in Dar es Salaam are: double parking, non-operating traffic lights, lack of sufficient feeder-roads, road accidents, and increased number of trucks with low speed in the roads, road works, and narrow roads. Likewise, it was found that many bumps in the road, many pedestrians crossing the roads, bad road conditions and the effects of rainfall. However, lack of road signs does not cause traffic congestion. Likewise, the findings show that traffic road congestion negatively affect the economic activities in Dar es Salaam Region. This is proved by the fact that congestion lowers the business turnover, increases fuel consumption to 
commuter buses and vehicles, affects the revenue among commuter buses and lower the daily earnings of commuter bus drivers and conductors. The findings also show that the road congestion affects the growth of the small and medium businesses by lowering the turnover, lowering the profit margins and sales, waste of the working/productive time and lowers the earnings of commuter workers, as well as increasing the fuel consumption, hence increasing the running costs. Moreover, lowers performances of various economic activities depending on the people who are caught in road traffic jams during peak hours in the morning and evening times. However, the study has found that road congestion in Dar es Salaam increases sales among small vendors selling their products to drivers and passengers who are stuck on congestion.

\subsection{Recommendations}

This study recommends the following:-

- Maintain and repair all roads that are in poor conditions. Likewise, pave to make them passable at all seasons, to reduce the congestion in the highways.

- Remove all traffic lights in some junctions and construct round about to reduce congestion and save time for waiting the green light while there no cars on the other side.

- Construct feeder-roads, flyovers and road interchanges in key junctions to reduce time and cost.

- Construct more, pedestrian bridges to reduce the number of people crossing the roads using zebras, and also provide adequate education to pedestrians to use the bridges to cross the roads.

- Introduce the use of camera where necessary to control speed where by an individual will be charged upon payment of insurances instead of using bumps; the use of mesh-like bumps should be avoided as they cause long traffic congestion and destroy/defect the vehicles.

- Expand roads to reduce congestion, and that all major roads leading to city centre should have at least three lanes on each side, which will make a total of six lanes for each road; this at least will reduce the congestion as huge volumes of vehicles will be able to pass at the same time.

\subsection{Areas for Further Studies}

This study aimed at assessing the effects of road congestion on economic activities in Dar es Salam region. The study did not assess the following areas which require further studies: The studies include the effects of road congestion on small businesses, the Effects of road congestion on formal workers' performance who hardly sleep at most 5 hrs as they wake up early to avoid congestion and got late at home.

\section{References}

Angus , E.R And Bertram O. (2019). Current Understanding of the Effects of Congestion On Traffic Accidents. International Journal Of Environmental Research And Public Health, Vol. 16, Issue 2.

Arnott, R. (2011), The Economic Theory of Urban Traffic Congestion: A Microscopic Research Agenda. Department Of Economics, Boston College, Usa.

Bailey,S. (2014). Measuring the Impact of Road Traffic Congestion from the UK Higher Education Sector. Records Management Journal, 16(3), pp.34-37.

Boldeanu, F.T and Constantinescu, L. (2015). The Main Determinants Affecting Economic Growth. Bulletin of the Transylvania University of Brasov, Vol.8, No.2

Bull, A. (2013). Traffic Congestion: The Problem and How to Deal With It. Economic Commission for Latin America, Working Paper, No.2

Chizonde, B. (2016). The Macroeconomic Determinants of Economic Growth In

Zambia: Do Copper Prices Matter? Munich Personal Repec Archive. Accessed At Www.Mpra.Ub.Un1Muenchen.De/87854 on 9th February 2020

Choi,J Coughlin J.F and D'ambrosio L. (2013). Travel time and subjective well-being Transportation. Research Board ,pp.100-108

Eddington, R, (2016). Transport Role in Sustaining the UK's Productivity and Competitiveness.

Elisonguo, A. D. (2013). The social-economic impact of road traffic congestion in Dar es

Salaam Region. Mzumbe University, Morogoro,

Hartgen, D .And Fields, G. (2017). Gridlock and Growth: The Effect of Traffic Congestion on Regional Economic Performance. Reason Foundation, Policy Summary of Study, No.371.

Kiunsi, R. B. (2013). A Review of Traffic Congestion in Dar es Salaam City from the

Physical Planning Perspective. Journal of Sustainable Development; Vol.6, No.2:2013.

Lomendra, V., Sharmila, P., Ganess, D. And Vandisha, N (2018). Assessing The Causes And Impacts of Traffic Congestion On The Society, Economy And Individual: A Case Of Mauritius As An Emerging Economy. Studies in Business and Economic No.13, Issue 3 Of 2018

Lu, I. J., Lewis, C. \& Lin, S. J. (2009.The Forecast of Motor Vehicle, Energy Demand and Co2emissionfrom Taiwan.Journal of Energy Policy, Road Transportation Sector. No. 37, Pp. 2952-2961. 
Maji,H.(2017). Identification of causes, types and locations of traffic congestion. International Journal for Urban studies, Vol 6 No 10 of October 2017.

Mpogole, H and Msangi, S. (2016). Traffic Congestion in Dar es Salaam: Implications of Workers' Productivity. Journal of Sustainable Development, Vol. 9, No.6:2016

Onyeneke, C., Chibuzor, E. And Charles, M (2018). Modeling The Effects of Traffic Congestion On Economic Activities-Accidents, Fatalities And Casualties. Journal For Biomedical Statistics and Informatics Vol.3, Issue 2, pp7-14

Osang, T. (2010). External and Internal Determinants of Development. Journal for Social Sciences, Vol.4, No.3 of May 2010

Raheem, S. B., Olawoore, W. A., Olagunju, D. P. \&Adeokun, E. M. (2015). The Cause, Effect and Possible Solution to Traffic Congestion On Nigeria Road.

Tilak, C. \& Reddy, R. R. (2016). Measurement of Traffic Congestion on High Dense Urban

Tanzania Transport Sector Review (2013). Transport and ICT Department. African

Development Bank Group.Tanzania

Upreti, P. (2015). Factors affecting economic growth in developing countries. Majaorthems in Economics, Vol.17, No.5 of May 2015 